\title{
El CRIMEN EN LA NOVELA NEGRA LATINOAMERICANA \\ "ENTRE LA FASCINACIÓN Y LA MEMORIA"
}

\author{
James Valderrama Rengifo* \\ Ministerio de Educación Nacional de Colombia
}

\section{Resumen}

En el presente artículo académico se realiza un acercamiento a la novela negra Latinoamérica desde dos perspectivas: la fascinación y la memoria.

El artículo establece una secuencia crítica que da cuenta de la evolución del género: sus regularidades y sus cambios literarios desde Edgar Allan Poe y Arthur Conan Doyle hasta los más destacados representantes del género negro en Latinoamérica, marcando la condición contemporánea de esta apropiación y desarrollo de este tipo de novelas. Posteriormente se postulan las claves de su análisis tomando referencias obras como Abril rojo del peruano Santiago Roncangliolo, Scorpio City del colombiano Mario Mendoza y Plata quemada de Ricardo Piglia, de Argentina.

Estas obras finalmente se proponen como un ejercicio de memoria donde ocurre un choque de ficciones en el que los hechos pasados adquieren un orden distinto porque aparecen otras voces, otros informes, testimonios, otros crímenes, otras víctimas, otros asesinos, otros detectives, etc. En este orden distinto, las marcas previas de la memoria chocan con las marcas nuevas que propone el relato. El centelleo resultante de ese choque de ficciones permite el acceso a otro conocimiento sobre el pasado y sus deudas con el presente y el futuro.

Palabras Clave: Crimen, complot, detectives, fascinación, memoria

Recibido: 19 de enero de 2016

Aprobado: 31 de marzo de 2016

*Licenciado en Literatura, con estudios en Prácticas Audiovisuales de la Universidad del Valle, Magister en Estudios Literarios de la Universidad Nacional. Actualmente trabaja para el Ministerio de Educación Nacional.

Dirección electrónica: jamesvaldere@hotmail.com 


\title{
The crime in the Latina American Black Novel "Between fascination and memory"
}

\begin{abstract}
This academic paper presents an approach towards the Latin America Black Novel from two perspectives: the fascination and the memory

This article establishes a critical sequence of the evolution of the genre: its regularities and literary changes since Edgar Allan Poe and Arthur Conan Doyle to the most prominent representatives of the black genre in Latin America; stressing the contemporary condition of this appropriation and the development of this type of novels. Subsequently, the keys to this analysis are proposed taking as references Abril Rojo by the Peruvian Santiago Roncangliolo, Scorpio City by the Colombian Mario Mendoza and Plata Quemada by Ricardo Piglia, from Argentina.

These literary works are finally proposed as a memory exercise where a clash of fictions occurs in which past events turn in a different order because other voices, other reports, testimonies, other crimes, other victims, other murderers and other detectives are incorporated in the picture. In this different order, the previous marks of memory collide with new marks proposed by the story. The resulting sparkle from this clash of fictions allows access to other knowledge about the past and its debts with the present and the future.
\end{abstract}

Key Words: Crime, Complot, Detectives, Fascination, Memory.

\section{Cómo citar este artículo}

APA: Valderrama, J. (2016). El crimen en la novela negra latinoamericana "entre la fascinación y la memoria". Poligramas, No. 42, junio. Pp.: 75-93

MLA: Valderrama, James. "El crimen en la novela negra latinoamericana "entre la fascinación y la memoria"'. Poligramas 42 (2016): pp. 75-93 Print.

ChicagoValderrama, James. 2016. El crimen en la novela negra latinoamericana “entre la fascinación y la memoria”. Poligramas 42 (junio): pp. 75-93 
La escritura y publicación de novelas negras se incrementó de manera considerable en Latinoamérica durante las últimas décadas del siglo XX y las primeras del siglo del siglo XXI. Evidencias de lo anterior se hallan en libros como El género negro de Mempo Giardinelli, Asesinos de papel de Lafforguey Rivera, Nombrar lo innombrable de Fernando Reati, Biografía de la novela negra de Rainov Bogomil, De la novela policíaca a la novela negra de Salvador Vásquez de Parga, Modernidad, posmodernidad y novela policial de Leonardo Padura Fuentes, Retóricas del crimen de Ezequiel Rosso, La novela policíaca en Colombia de Hubert Poppel y La ley y el crimen de Sonia Mattalia, donde se hace referencia a un gran número de novelas negras publicadas entre las décadas antes mencionadas por autores como Rubén Fonseca (Brasil), Santiago Roncagliolo (Perú), Ricardo Piglia (Argentina), Mempo Giardinelli (Argentina), Paco Ignacio Taibo II(México-España), Ramírez Heredia (México), Ramón Díaz Eterovic (Chile), Roberto Ampuero (Chile), Dante Liano (Guatemala), Leonardo Padura Fuentes y Lorenzo Lunar (Cuba), Mario Mendoza y Nahum Montt (Colombia), entre otros.

Las causas de ese incremento en la escritura y publicación de estas novelas se deben sin duda a múltiples variables. Entre estas se destaca el creciente interés de los escritores en este tipo de novelas para dar cuenta estéticamente de flagelos como la corrupción, el narcotráfico o las dictaduras, debido a que las características del género negro, o policíaco ${ }^{1}$, facilitan el tratamiento literario de estos fenómenos sociales. Otra variable, que complementa la anterior, es la buena recepción de los lectores de estas novelas debido a cierta apetencia por el complot, la trampa, la violencia, la intriga, la ilegalidad, la injusticia, la impunidad y, por supuesto, el crimen.

Estas dos variables parecieran coincidir con lo que Alejo Carpentier (1982) planteó, parafraseando a Chesterton, como la idea de fascinación por el crimen en su "Apología a la novela policíaca", en donde propone al criminal como un creador y al detective como alguien que explica su creación. En palabras de Carpentier el criminal es un artista y el detective un crítico de arte: 
Pero pronto los novelistas de este género se dieron cuenta de algo muy importante: el delincuente, el bandido genial, puede resultar mucho más lleno de interés que el sabueso que le muerde incansablemente los talones. No debe olvidarse que el criminal tiene una superioridad filosófica sobre el detective. El criminal aparece como elemento creador (...) Su acto altera un equilibrio preestablecido, colocando a sus semejantes ante un hecho originado por su voluntad. Este acto de afirmación equivale a la creación de un problema (...) El detective encuentra un problema perfectamente planteado, que excluye toda creación de su parte, y del que solo puede explicarnos el mecanismo, si acierta en su tarea investigadora. El detective es al delincuente lo que el crítico de arte es al artista; el delincuente inventa, el detective explica (...) una vez realizado su delito, lucha solo contra un organismo maravillosamente disciplinado (...) El bandido se basta a sí mismo, mientras la policía moviliza todo el aparato de los laboratorios médico-legales, toda sus jauría de inspectores, todo su arsenal de pistolas y ametralladoras, para acosar y derribar a un solo hombre (...) bajo el signo de una policía que deja escapar una cantidad pavorosa de delincuentes en el mundo entero, mientras se preocupa en arrestar y aplastar bajo sus botas a todo infeliz ciudadano sospechoso de tener una ideología libre en materia de política. (187)

Este enaltecimiento del crimen como una creación estética lo aleja de connotaciones éticas y morales $\mathrm{y}$, por consiguiente, facilita cierto acercamiento al género desde la fascinación por el crimen y el criminal. Esta idea subversora de Carpentier es apuntalada posteriormente por escritores como los congregados en «La Semana Negra de Gijón» por Paco Ignacio Taibo II y por Gustavo Forero Quintero ${ }^{2}$ (2013) en su ensayo "Indefiniciones y sospechas del género negro", cuando advierte de la fascinación en las novelas negras:

Desde Edgar Allan Poe, Sir Arthur Conan Doyle y Ross Macdonald, hasta las últimas novelas de Ramón Díaz Eterovic en Chile, Osvaldo Soriano y Ricardo Piglia en Argentina y Rubem Fonseca en Brasil, Leonardo Padura Fuentes y Lorenzo Lunar en Cuba y Mario Mendoza en Colombia, las obras «negras» no solo dan cuenta de un fenómeno comercial, sino también de una rara fascinación social por el crimen. (p. 25).

Por consiguiente, la apetencia estética de lectores y escritores hacia esta literatura estaría determinada por la afinidad con el universo 
criminal y todo lo que lo constituye. Desde la perspectiva de Forero y de los congregados en «La Semana Negra de Gijón», pareciera que el interés hacia estos relatos no hubiese cambiado desde Edgar Allan $\mathrm{Poe}^{3}$ y Arthur Conan Doyle ${ }^{4}$ hasta nuestros escritores latinoamericanos contemporáneos.

Ante la fascinación planteada por los estudios literarios antes mencionados, quiero advertir sobre otra tendencia, menos destacada, en la novela negra latinoamericana: la memoria. Pero antes de precisar cómo se presenta esta tendencia en nuestras latitudes, es necesario acercarnos a la evolución del género para una mayor comprensión; por ejemplo, al analizar la obra de Poe y Doyle encontramos que sus narradores relataban expertos procesos de investigación direccionados por sobrenaturales investigadores; en esas narraciones se leía cómo los investigadores Dupin y Holmes resolvían enigmáticos crímenes desde sus aposentos sin aventurarse a las calles. Estos elegantes detectives resolvían los crímenes a través de sofisticados juegos mentales que lindaban con la precisión matemática y la rigurosidad científica. Ningún aspecto quedaba por fuera del control de los detectives y de los procesos de investigación que llevaban a cabo. Estos personajes se destacaban, entre otros aspectos, por su agudeza mental, por su pertenencia a estratos sociales altos y su apetencia recreativa a la solución de crímenes que desbordaban la inteligencia del aparato policial. En estos primeros relatos el crimen se manifestaba como algo intempestivo, al margen de sociedades estables y confiables; por ello la aparición del crimen rompía el equilibrio social y solo se restablecía cuando el detective descubría al criminal. En los relatos de estos dos autores el crimen era un evento extraño a la naturaleza de los sistemas sociales representados en sus obras. Por consiguiente, es fácil adherirse a la idea de que a los lectores londinenses y norteamericanos del siglo XIX les fascinaban los crímenes que hallaban en esos relatos, se les hacía divertido e interesante leer relatos donde finalmente el equilibrio social prevalecía.

Esta fascinación se hizo más evidente en escritores y lectores cuando posteriormente los procesos investigativos salieron de los despachos herméticos de los detectives hacia salones de grandes mansiones, a 
escenarios un poco más abiertos y poblados de otros participantes en los delitos. Las tramas se hicieron más extensas y truculentas, por ello se pasó del cuento a la novela dando mayor importancia al diálogo como recurso literario. En consecuencia de lo anterior, se hicieron más explícitos procesos investigativos como las audiencias e interrogatorios. A pesar de aquellos cambios, estas novelas siguieron conteniendo características de los relatos iniciales de Poe y Doyle como el divertimento intelectual para el lector, basado en mecanismos racionales de anticipación y cuyo atractivo estaba en la abierta competencia entre el detective y el criminal. Estas novelas atrapaban al lector con un desafío lógico y se centraban en las habilidades intelectuales de los detectives, enarbolando así la intelectualidad como la condición esencial del ser humano moderno. Entre los representantes de esos cambios literarios en las novelas policíacas están Agatha Christie (británica), Maurice Leblanc (francés), Georges Simenon (Belga), Edgar Wallace (británico), entre otros. Hasta aquí la fascinación estaba orgánicamente relacionada con el divertimento mediante un reto intelectual a los lectores: todos querían descubrir, antes que el detective, al criminal.

Esta perspectiva cambia a partir de la aparición de Dashiell Hammett y Raymond Chandler ${ }^{5}$ en Norteamérica en la primera mitad del siglo XX, en la medida en que comienza desfigurarse la línea divisoria entre el bien y el mal, entre la legalidad y la ilegalidad. Los personajes de estas obras no se caracterizan por ser buenos o malos, sino que presentan comportamientos ambiguos, ruines y peligrosos. Los detectives se asemejan a los delincuentes y la crudeza del crimen se vuelve más explícita. El acento sobre el proceso investigativo se atenúa y la impecabilidad moral de los personajes que representan la ley y el Estado se diluye; ya no están por encima de los delincuentes ni ética ni moralmente. El realismo del mundo narrado aumenta en medida proporcional al abandono del juego lógico de las causas y los efectos. El divertimento intelectual desde la ficción comienza a ser sustituido por una crítica social con pretensiones realistas. De tan profunda dimensiones son estos cambios literarios que estas novelas comienzan a ser nombradas bajo una nominación distinta al género policíaco. Asistimos entonces a lo que se conoció como novela dura o novela negra ${ }^{6}$. 
En las novelas negras de Hammett y Chandler las acciones tienen móviles más ambiguos y éstos no se develan al final de la novela, como en las obras de Poe, Doyle, Christie, Leblanc, Simenon y Wallace, sino a través de todo el relato. Ya no importan las causas sino los efectos. No importa por qué un personaje pudo hacer lo que hizo, sino qué cosas suceden luego de que lo hizo. Lo anterior no quiere decir que a veces las causas no sean enunciadas, sino que estas siempre tienen la forma de una manifestación exterior de algo más profundo e inexplicable. En las novelas negras de Hammett y Chandler, la excepcionalidad de los detectives y sus expertos procesos de investigación son sustituidos por el crimen como componente esencial de las mismas, proponiendo así una ficción que problematizaba la realidad norteamericana de mediados del siglo XX.

En este punto nos distanciamos de las sociedades ideales de la tradicional novela policíaca, de su enfoque moralizante y nos acercamos de manera cruda y brutal a la representación de sociedades decadentes y sórdidas, donde el crimen es parte orgánica de su naturaleza.

En Latinoamérica la manifestación del género policíaco se da en la primera mitad del siglo XX, a partir de las revistas y de las obras de Antonio Helú (México), Jorge Luis Borges y Adolfo Bioy Casares (Argentina). Ezequiel de Rosso (2011) dice al respecto:

Según consenso general, el origen del género policial en la literatura latinoamericana puede situarse entre la década del treinta y del cuarenta (...) Selecciones policíacas y de misterio (revista especializada en la que se dan a conocer autores locales) comienza a publicarse en México dirigida por Antonio Helú en 1946; en 1945, Jorge Luis Borges y Adolfo Bioy Casares empiezan a editar en Buenos Aires "El Séptimo Circulo" (una colección de novelas policiales que incluye autores argentinos y notas de los editores y sus allegados -como Manuel Peyrou- sobre los diferentes volúmenes). (p. 13)

Sin embargo, al final del siglo XIX ya se había dado a conocer la obra La bolsa de huesos de Eduardo Holmberg (Argentina), en 1903, El triple robo de Bellamore del uruguayo Horacio Quiroga (publicación en la revista Caras y Caretas) y entre 1913 y 1921, Alberto Edwards publica en Pacífico Magazine relatos protagonizados por su detectives 
Román Calvo -el Sherlock Holmes chileno-, pero estos y otros textos son fenómenos aislados que, en su momento, no definían un campo de operación del género. Esta definición comienza a gestarse en 1933 cuando Xavier Villaurrutia, Alfonso Reyes, Jorge Luis Borges y Juan Carlos Onetti construyen un conjunto de argumentos en torno a la novela policíaca, en donde reivindican la cualidad formal del relato policial. Borges (2001) dice lo siguiente en "Leyes de la narración policial": La organización y la aclaración, siquiera mediocres, de un algebraico asesinato o de un doble robo, comportan más trabajo intelectual que la casera elaboración de sonetos perfectos o de molestos diálogos entre desocupados griegos (...)" (15)

Estos argumentos continúan presentándose en los años sucesivos en prólogos y revistas, planteando dos tendencias iniciales en la forma de naturalización del género en Latinoamérica: la copia y la parodia. En cuanto a la copia encontramos argumentos como el de Xavier Villaurrutia que dice lo siguiente en el prólogo de La obligación de asesinar (primer libro de cuentos policiales en México) de Antonio Helú (1992):

Con relación a la novela-ensayo, a la novela biografía, a las biografías novelas, las novelas policíacas tiene la ventaja de ser, al menos, policíacas, lo que equivale, de una vez por todas, a asegurar un alimento más o menos rico en las substancias que el lector busca para su nutrición. (p.16)

De manera similar, el poeta vanguardista Vicente Huidobro escribe con Hans Arp El jardinero del castillo de media noche bajo las pretensiones formales del relato policial. En relación con la otra tendencia, "la parodia", hallamos la colección de cuentos Seis problemas para don Isidro Parodi de Jorge Luis Borges y Adolfo Bioy Casares publicada en 1942. Sobre estas dos tendencias de naturalización de la novela policíaca en nuestras latitudes, Leonardo Padura Fuentes (2000) nos advierte lo siguiente en su libro "Modernidad, posmodernidad y novela policial:

No debe ser extraño que sean precisamente dos autores ligados a la vanguardia literaria, con intereses artísticos que desbordan lo genérico del policial, quienes se encarguen de asumir esta "naturalización" que 
se concreta por dos vías: la estructural- a través de la parodia- y la formal-por medio del lenguaje. Al colocar a Isidro Parodi (y su apellido no puede ser una casualidad, tratándose precisamente de Borges y Bioy, Parodi-Parodia) en una celda, desde la cual debe develar intrincados misterios, los autores toman lo esencial del modelo creado por Poe (Dupin en su habitación), magnificado por Doyle (Holmes en su sala de estar) y llevado a alturas filosóficas por Chesterton (la teología del padre Brown) y lo asumen, deformándolo: Parodi en una cárcel. (p.131)

Asimismo, como ya lo he señalado anteriormente, Alejo Carpentier contribuye a fijar características del género policial en Latinoamérica, pero con una tendencia más cercana al mundo criminal que al mundo detectivesco. Esta idea de Carpentier, junto a la parodia como camino de naturalización, desplazan el interés acerca del proceso investigativo del detective hacia el proceso creador del criminal en Latinoamérica. Pero dicho desplazamiento no obedece solo a la fascinación como aduce Carpentier, sino también a la memoria.

Entre 1951 y 1953 aparecen las primeras antologías de cuentos policíacos: Antología de los mejores cuentos policíacos de José Navasal (Chile), Diez cuentos policiales argentinos de Rodolfo Walsh y Los mejores cuentos policíacos mexicanos de María Elvira Bermúdez. De estas antologías emerge una nueva preocupación crítica acerca del género policíaco y es la excelencia en el estilo, es decir, que un texto policíaco no puede ser valorado únicamente por reproducir la tradición formal del género (el sofisticado juego mental con precisión matemática y rigurosidad científica, entre otros aspectos ya señalados) sino por sus búsquedas estéticas que conlleven a la creación de nuevas poéticas latinoamericanas; diferenciándose oportunamente de la novela negra norteamericana por su compromiso con lo político.

Esta intención de renovación de los escritores latinoamericanos es la que hace que la estructura del género policíaco se transforme. Un primer resultado de esas nuevas exploraciones fue Operación Masacre ${ }^{7}$ de Rodolfo Walsh en 1957, obra en la cual se novela un hecho real: el fusilamiento de civiles argentinos en el basural de José León Suárez por alzarse contra el gobierno de facto del general Pedro Eugenio Aramburu. Obras como Operación masacre hacen explícita una 
certeza que definirá posteriormente la escritura de novelas negras en Latinoamérica: los escritores y lectores no aceptan que en una novela negra latinoamericana el detective logre restablecer el equilibrio social. La memoria de escritores y lectores latinos está atravesada por una historia de impunidad y de injusticia que se desprenden de flagelos como la corrupción, el narcotráfico, las dictaduras, entre otros. Por consiguiente, lo que determina nuestra relación con la novela negra en Latinoamérica no es solamente la fascinación sino también la memoria, debido a que compartimos pasados con deudas, preguntas y múltiples crímenes sin resolver.

En razón de lo anterior, en las novelas emerge una verdad aterradora que no se dice pero que está ahí: el crimen evidencia complejas relaciones entre el mundo criminal y los poderes políticos que presiden los Estados latinoamericanos representados en las obras literarias. En este sentido, estas novelas plantean historias alrededor del crimen y este, a su vez, encierra preguntas de difícil solución, más allá de la contraposición entre el detective y el criminal. El crimen se presenta como un tejido de pequeños sucesos que contienen en sí mismos una verdad no visible ${ }^{8}$ (pero que está ahí) acerca de los sistemas sociales representados en las novelas. Los interrogantes superan al detective y al proceso de investigación, ya no solo existe la necesidad de una explicación magistral que descifre al culpable, sino también que descubra la naturaleza misma del crimen y sus relaciones con lo político.

Acerca de esta relación entre la literatura y lo político Fernando Reati (1985) en Nombrar lo innombrable. Violencia política y novela argentina, propone siguiente al respecto:

Mientras que la novela histórica habla sobre el presente político a través de un desplazamiento cronológico hacia el pasado, otra narrativa, la policial, hace lo mismo por medio de un desplazamiento de género (...) Los tópicos clásicos del género policial (...) se prestan a un discurso desplazado, más o menos eufemístico, que al hablar sobre el submundo de la delincuencia y su contraparte policíaca, se refiere también a la lucha por el poder político. (p.167)

El crimen se presenta entonces como la mayor manifestación del declive moral en las novelas negras latinoamericanas; por eso su 
crudeza y atrocidad sustituyen los procesos investigativos que antes eran los ejes estructurantes en las novelas policíacas. Debido a ello la novela negra latinoamericana no centra su estética en la construcción de detectives sobrenaturales, sino en el crimen como eje estructurante de la misma.

En razón de lo anterior, la novela negra latinoamericana estaría determinada por la historia de sus sistemas sociales, por la anomia que estos han construido en relación con los abusos de poder de las democracias y de las dictaduras e, igualmente, con la conexión de esos sistemas sociales con la corrupción, la violencia, la impunidad y por supuesto el crimen.

Paco Ignacio Taibo II ${ }^{9}$ en la Semana negra de Gijón del 2003 y Mempo Giardinelli ${ }^{10}$, advierten que la novelas negras son manifestaciones de un género llamado a convertirse en un mecanismo de denuncia, o mejor aún, en un mecanismo de reflexión sobre nuestras realidades. Pero algunos expertos de la Semana negra de Gijón del 2003 fueron un poco más allá cuando propusieron que la novela negra planteaba el crimen como una respuesta a sociedades corruptas y violentas; es decir, el crimen como una respuesta a los discursos oficiales y, en especial, a los crímenes de Estado. Por lo tanto, las novelas en sí mismas serían un mecanismo de denuncia como consecuencia de los abusos del poder de los sistemas sociales y políticos latinoamericanos.

Sin embargo, reducir estas novelas a denuncias, en mi criterio, las despoja de sus estatus como obras de arte porque sus tratamientos literarios van más allá de la denuncia de los poderes corruptos representados en las mismas; sus estrategias narrativas no se reducen a denunciar el horror ejecutado por los poderes políticos, sino a reconstruir un relato sobre el pasado y, desde este, sobre el presente y el futuro de las sociedades representadas en las obras. Es decir, que el desplazamiento planteado hacia lo criminal en estas novelas se debe al compromiso con la memoria y no solo a la fascinación por el crimen como ocurría a finales del siglo XIX y principios del XX.

Novelas como Abril rojo de Santiago Roncangiolo, Plata quemada de Ricardo Piglia y Scorpio City de Mario Mendoza, entre otras de Ramón Díaz Eterovic (Chile), Roberto Ampuero con su detective 
Cayetano Brulé (Chile), Rubén Fonseca (Brasil), Mempo Giardinelli (Argentina), Paco Ignacio Taibo II (México-España), Ramírez Heredia (México), Ramón Díaz Eterovic (Chile), Dante Liano (Guatemala), Leonardo Padura Fuentes, Lorenzo Lunar (Cuba) o Nahum Montt (Colombia), plantean una estrecha relación entre literatura y política, a partir de la construcción relatos de ficción alternativos que proponen nuevas relaciones entre el pasado, el presente y el futuro.

En el caso de Abril rojo, Plata quemada y Scorpio city el pasado es una referencia fundamental: en Abril rojo la dictadura en Perú de Alberto Fujimori (1900-2000), en Scorpio city las limpiezas sociales por Escuadrones de la muerte en Colombia (1900-2000) y en Plata quemada la tensión resultante de la proscripción de Juan Domingo Perón en Argentina (1960-1970). Los relatos que se desprenden del pasado de las sociedades representadas en las novelas están determinados en las mismas por relaciones de poder que implican un ejercicio de control sobre lo que se sabe acerca de ese pasado (complot estatal). Ahora bien, cuando la narración de las novelas trae un pasado que ya no está, se plantea una recreación del pasado en el presente de la narración de las novelas. Por consiguiente, en Abril rojo, Scorpio city y Plata quemada se recrea el recuerdo de un pasado, a partir de unas formas específicas de narrar, en un presente de la narración. Las novelas entonces están planteando una forma de acceder al pasado: son una experiencia temporal que propone un ejercicio a través de la memoria (relación entre el pasado, presente y futuro).

Pero ¿cómo funciona el dispositivo de la memoria en estas tres novelas? Para dar una respuesta satisfactoria es necesario ver estas obras a través de la óptica de Tzvetan Todorov (2000), en su obra Los abusos de la memoria, cuando aborda el concepto de memoria como una interacción entre la supresión y la conservación del pasado que contiene dentro de sí misma una selección:

En primer lugar hay que recordar algo evidente: que la memoria no se opone en absoluto al olvido. Los dos términos para contrastar son la supresión (el olvido) y la conservación; la memoria es, en todo momento y necesariamente, una interacción de ambos. El restablecimiento integral del pasado es algo por supuesto imposible (pero que Borges 
imaginó en su historia de Funes el memorioso) y, por otra parte, espantoso; la memoria, como tal, es forzosamente una selección: algunos rasgos del suceso serán conservados, otros inmediata o progresivamente marginados, y luego olvidados. (p.15)

En este orden de ideas, la narración en Abril rojo, Plata quemada y Scorpio city propondría un conjunto de selecciones sobre unos pasados representados en las mismas, a través de un relato que trae esos pasados a un presente de la narración. Frente a este uso de la memoria Todorov (2000), en Los abusos de la memoria, nos ilustra:

A partir de lo dicho, se impone una primera distinción: la que hay entre la recuperación del pasado y su utilización subsiguiente. Puesto que es esencial constatar que ningún automatismo vincula ambos gestos: la exigencia de recuperar el pasado, de recordarlo, no nos dice todavía cuál será el uso que se hará de él; cada uno de ambos actos tiene sus propias características y paradojas. Esta distinción, por neta que sea, no implica aislamiento. Como la memoria es una selección, ha sido preciso escoger entre todas las informaciones recibidas, en nombre de ciertos criterios; y esos criterios, hayan sido o no conscientes, servirán también, con toda probabilidad, para orientar la utilización que haremos del pasado. (p. 17)

Estos conceptos de recuperación y uso se complementan con las características de la memoria, sus relaciones con la construcción de la identidad y con el relato, planteadas por Paul Ricoeur (2000) en $L a$ memoria, la historia y el olvido:

En el plano más profundo, el de las mediaciones simbólicas de la acción, la memoria es incorporada a la construcción de identidad a través de la función narrativa. Y como la configuración de la trama de los personajes del relato se realiza al mismo tiempo que la historia narrada, la narración contribuye a modelar la identidad de los protagonistas de la acción al mismo tiempo que los contornos de la propia acción (p. 115).

Es decir que la construcción del relato determina la recuperación del pasado perteneciente a las sociedades representadas en las novelas, y, por consiguiente, en Abril rojo, Scorpio City y Plata quemada se recupera el pasado mediante la narración de crímenes atroces, del complot 
del Estado detrás de los mismos, y de las relaciones de poder entre las fuerzas que se enfrentan.

El crimen y el complot son narrados a través de relatos que contiene el uso de diversos textos, narradores y voces que permiten elaborar una imagen del pasado desde múltiples puntos de vista. Brauer (2002) afirma: "Los hechos del pasado han desaparecido. Decimos que de algún modo 'se conservan' en nuestros recuerdos, con lo que queremos indicar no la presencia de ellos mismos sino de su imagen en nosotros" ( $\mathrm{p}$. 47).

Ahora bien, esta imagen del pasado contiene deudas en razón de la verdad y la justicia. Sobre estas deudas es importante apoyarse en algunos otros planteamientos de Ricoeur (2000) en La memoria, la historia y el olvido:

(...) ha llegado el momento de hacer intervenir otro concepto nuevo, el de la deuda, que es importante no reemplazar por el de culpabilidad. La idea de deuda es inseparable de la herencia. Debemos a lo que nos precedieron una parte de lo que somos. El deber de la memoria no se limita a guardar una huella material, escrituraria u otra, de los hechos pasados, sino que cultiva el sentimiento de estar obligados respecto a estos otros que afirmaremos más tarde que ya no están pero que estuvieron. (p. 120)

En el caso de la novelas mencionadas los pasados representados contienen estas deudas, en la medida que la narración da cuenta de crímenes y criminales sin castigo. Es decir, las novelas contienen pasados que persiguen y por ello el deber de la memoria, como relato, es contribuir a la verdad y a la justicia. Ricoeur(2000) en La memoria, la historia y el olvido, vuelve a ilustrarnos:

Se plantea, pues, la cuestión de saber lo que proporciona la idea de justicia su fuerza federativa tanto respecto al objetivo veritativo y al objetivo pragmático como respecto al trabajo de la memoria y al trabajo del duelo. Lo que hay que examinar es la relación del deber de memoria con la idea de la justicia. (Ibíd. 120)

Las novelas entonces construyen un relato en el que se trae al presente de la narración una deuda del pasado, y que logran, más allá 
de la denuncia, construir otro sentido, otra forma de habitar ese pasado en el presente de las narraciones y en el futuro de posteriores lecturas de estas novelas.

Frente a la relación de la memoria, la verdad y la justicia, Ricoeur (2000) afirma: "Es la justicia la que, al extraer de los recuerdos traumatizante su valor ejemplar, transforma la memoria en proyecto; y es este mismo proyecto de justicia el que da al deber de la memoria la forma del futuro del imperativo" (p. 119)

En razón de lo anterior, las deudas del pasado reconstruido en el relato se desprenden de un conflicto social y político que, a su vez, se desprende de una lucha por el poder. Por lo tanto, la construcción de ese sentido, desde la narración de las novelas mencionadas, plantea una relación entre la literatura y la política, a través de la interacción de un pasado representado en un presente narrativo para la construcción de futuros relatos.

Sobre esta relación Ricardo Piglia (2013) plantea las siguientes ideas en el texto Tres propuestas para el próximo milenio (y cinco dificultades):

A diferencia de lo que se suele pensar, la relación entre la literatura -entre novela, escritura ficcional- y el Estado es una relación de tensión entre dos tipos de narraciones. Podríamos decir que también el Estado narra, que también el Estado construye ficciones, que también el Estado manipula ciertas historias. $\mathrm{Y}$, en un sentido, la literatura construye relatos alternativos, en tensión con ese relato que construye el Estado, ese tipo de historias que el Estado cuenta y dice.

Por consiguiente, Abril rojo, Plata quemada y Scorpio City, entre otras, proponen una ficción desde la reconstrucción del pasado que confronta la ficción de los Estados representados en las mismas. En este sentido, el ejercicio de la memoria plantea un choque de ficciones donde los hechos pasados adquieren un orden distinto porque aparecen otras voces, otros informes, testimonios, otros crímenes, otras víctimas, otros asesinos, otros detectives, etc. En este orden distinto, las marcas previas de la memoria chocan con las marcas nuevas que propone el relato. El choque de estas ficciones permite el acceso a otro conocimiento sobre 
el pasado y sus deudas con el presente y el futuro. Este choque produce centellas, como lo propone Foucault en su conferencia La verdad y las formas jurídicas (p.7, 8), la memoria no queda depositada en ningún museo, sino que estalla y se re-crea desde la atrocidad de los crímenes y desde la complejidad de los complot Estatales detrás del mismos, para sacudir la historia de las sociedades representadas en estas novelas negras latinoamericanas.

1. Estas características se plantean desde la taxonomía planteada por Todorov en su ensayo Tipología del relato policíaco, en la cual determina que este género alberga distintas modalidades narrativas, entre ellas, la novela negra.

2. Profesor de literatura dela Universidad de Antioquia. Doctor "Cum Laude" en literatura Española e Hispanoamericana por la Universidad de Salamanca y Magister en estudios Romances de la Universidad de la Sorbona (París IV). Entres su libros se destacan Crimen y control y La anomia en la novela de crimenes en Colombia. Es el director del Congreso Internacional de literatura "Medellín negro".

3. Edgar Allan Poe (1809-1849) es considerado el creador de género debido a sus tres historias protagonizadas por el investigador francés Dupin: Los crimenes de la calle Morgue, El misterio de Marie Roget y La carta robada.

4. Arthur Conan Doyle (1859-1930), creador del popular personaje Sherlock Holmes, el investigador victoriano de Baker Street, es el protagonista de novelas como Estudio en escarlata, El signo de los cuatro o El sabueso de los Baskerville.

5. Dentro de las obras de Raymond Chandler están El sueño eterno, Adiós muñeca, El largo adiós, La ventana siniestra, La dama del lago, Playback y La hermana menor, y algunos relatos cortos publicados en la revista Dime Detective Magazine. Recuperado de: https://es.wikipedia.org/wiki/ Raymond_Chandler. Consultado el 28 de agosto. 9:30 PM.

6. La expresión novela negra o romane noir se ha relacionado con la literatura de posguerra de los $40 \mathrm{~s}$ y $50 \mathrm{~s}$ y se dice que comenzó con la série noire thrillers criminales de Marcel Duhamel. Sin embargo, la novela negra o romane noir se originó en los 30s en la revista norteamericana Black Mask que se especializaba en historia de crímenes. En esta revista fueron célebres Hammett y Chandler por la crudeza de sus relatos. 
7. Curiosamente Operación masacre se publica nueve años antes de A sangre Fría de Truman Capote, sin obtener el reconocimiento de esta última.

8. Foucault, Michel. Las palabras y las cosas. Buenos Aires: Siglo Veintiuno Editores: 1968. Recuperado de: http://www.uruguaypiensa.org.uy/imgnoticias/682.pdf.

9. Paco Ignacio Taibo II (Gijón, 1949) es un escritor asturiano-mexicano. Ha sido tres veces ganador del Premio «Dashiell Hammett», otorgado a la mejor novela negra, y ganador del Premio Planeta en 1982. Es director y fundador de «La Semana Negra de Gijón», un certamen anual que atrae a la mayoría de los grandes escritores del género negro mundial.

10. Giardinelli hace alusión a la relación arte y política en una entrevista concedida a Goran Tocilovac del diario El Comercio (Lima, Perú).Suplemento dominical, 31 de octubre de 2004.

http://www.mempogiardinelli.com/entre6-genero-negro.htm. Consultado el 28 de agosto. 9:30 PM.

\section{Referencias bibliográficas}

Bermúdez, M. (1955). Los mejores cuentos policíacos mexicanos. México D.F.: Libro Mex.

Bogomil, R. (1978). Biografía de la novela negra. La Habana: Editorial Arte y Literatura.

Borges, J.L. (2001). “Las leyes de la narración policial”. En Textos recobrados 1931-1955. Barcelona: Emecé.

Borges, J.L. (1979). Seis problemas para don Isidro Parodi (1946). Con Adolfo Bioy Casares: Obras completas en colaboración (pp. 11-121). Buenos Aires: Emecé editores.

Capote, T. (2001). A sangre fría. Barcelona: Anagrama.

Edwards, A. (1953). Román Calvo. El Sherlock Holmes Chileno. Santiago: Pacífico.

Brauer, D. (2002) “La fragilidad del pasado". En M. Cruz (comp.), Hacia dónde va el pasado. Buenos Aires: Paidós.

Carpentier, A.(1982) “Apología de la novela policíaca”. En L.R. Nogueras (comp.), Por la novela policíaca. La Habana: Editorial Arte y Literatura.

Forero Quintero, G. (2013). "Indefiniciones y sospechas del género negro".

En Hojas Universitarias. Recuperado de: http://issuu.com/mireyinn/docs/ indefiniciones

Foucault, M. (2013). La verdad y las formas jurídicas. Recuperado de: http:// www.posgrado.unam.mx/arquitectura/aspirantes/La_verdad.pdf 
Giardinelli, M. (2004) El género negro. El Comercio (Lima, Perú): Suplemento dominical, 31 de octubre.

Góngora, A. \& Suárez, C. (2013). Por una Bogotá sin mugre: violencia, vida y muerte en la cloaca urbana. Recuperado el 29 mayo 2013 de: http://www. javeriana.edu.co/facultades/c_sociales/universitas/66/05gongora.pdf

Helú, A. (1992) La obligación de asesinar. México: CNCA.

Holmberg, E. (2013). La bolsa de huesos. Biblioteca Virtual Raúl Barón Biza, restauración digital. Recuperado el 29 de mayo de 2013 de: http:// es.scribd.com/doc/57456647/HOLMBERG-La-Bolsa-de-Huesos

Huidouro, V. \& Arp, H. (1935). El jardinero del castillo de media noche. Tres inmensas novelas. Santiago de Chile: Editorial Zigzag.

Lafforgue, J. y Rivera, J. (1996). Asesinos de papel: ensayos sobre narrativa policial. Buenos Aires: Colihue.

Mattalía, S. (2008). La ley y el crimen. Usos del relato policial en la narrativa argentina (1880-2000). Madrid: Iberoamericana/Vervuert.

Mendoza, M. (1998). Scorpio city. Bogotá: Planeta colombiana editorial s.a..

Navasal, J. M. Antología de los mejores cuentos policíacos. Santiago de Chile: Zigzag.

Padura Puentes, L. (2000). Modernidad, posmodernidad y novela policíaca. La Habana: Ediciones Unión.

Piglia, R. (2013a). Plata quemada. Barcelona: Anagrama

Piglia, R. (2013). Tres propuestas para el próximo milenio (y cinco dificultades). Recuperado el 29 de mayo de 2013 de: http://www.casa.cult. $\mathrm{cu} /$ publicaciones/revistacasa/222/piglia.htm>

Piglia, R. (2013b). Teoría del complot. Transcripción de la conferencia dictada el 15 de julio de 2001 en la Fundación Start de Buenos Aires. Recuperado el 29 de mayo de 2013 de: http://es.scribd.com/ search?query $=$ teor $\%$ c $3 \%$ ada + del + complot + de + piglia

Poppel, H. (2001). La novela policíaca en Colombia. Medellín: Universidad de Antioquia.

Quiroga, H. (2013). El triple robo de Bellamore. Revista de Letras de la Biblioteca Nacional de la República Argentina. Recuperado el 29 de mayo de 2013 de: http://www.bn.gov.ar/abanico/A50802/quiroga-robo.html

Reati, F. (1985). Nombrar lo innombrable. Violencia política y novela argentina. Buenos Aires: Legasa.

Ricoeur, P. (2000). La memoria, la historia y el olvido. Buenos Aires: Fondo de cultura económica.

Rojas, C. (1984). La violencia llamada «limpieza social». Bogotá: Cinep.

Roncangiolo, S. (2006). Abril rojo. Lima: Alfaguara.

Rosso, E. (2011). Retóricas del crimen, reflexiones latinoamericanas sobre el género policial. Alcalá: Alcalá grupo editorial y distribuidor de libros. 
Poligramas 42 - junio de 2016

Todorov, T. (2000). Los abusos de la memoria. Barcelona: Paidós Asterisco. Vásquez de Parga, S. (1986). De la novela policíaca a la novela negra. Plaza y Janes editores.

Velásquez, D. (1656). Las meninas. Óleo sobre lienzo. Museo del Prado: Madrid.

Walsh, R. (1953a). Diez cuentos policíacos argentinos. Buenos Aires: Hachette. Walsh, R. (1964b). Operación masacre. Buenos Aires: Editorial Continental. 